American Journal of Neuroscience 2 (2): 65-69, 2011

ISSN 1948-9900

(C) 2011 Science Publications

\title{
Effects of Aluminium Chloride on Anxiety-Related Behaviour
}

\author{
${ }^{1}$ Buraimoh, A.A., ${ }^{2}$ S.A. Ojo, ${ }^{2}$ J.O. Hambolu and ${ }^{1}$ S.S. Adebisi \\ ${ }^{1}$ Department of Human Anatomy, \\ Faculty of Medicine, Ahmadu Bello University, Zaria, Nigeria \\ ${ }^{2}$ Department of Veterinary Anatomy, \\ Faculty of Veterinary Medicine, Ahmadu Bello University, Zaria, Nigeria
}

\begin{abstract}
Problem statement: Aluminium is presents in many manufactured foods, medicines and is also added to drinking water for purification purposes. It has the potential to be neurotoxic in human and animals but its contribution in Alzhemer's disease remains contradictory. Anxiety affects oneeighth of the total population world-wide and has become an important area of research interest in psychopharmacology. Approach: The present study was aimed at evaluating the effects that Aluminium chloride could have on anxiety-related Behaviour of Adult wistar Rats. A total of Ten (10) Adult wistar rats were used for this experiment. The wistar rats were divided into five groups: Group I was the control that received distil water, Group II received $475 \mathrm{mg} \mathrm{Kg}^{-1}$, Group III received $950 \mathrm{mg}$ $\mathrm{kg}^{-1}$, Group IV received $1,425 \mathrm{mg} \mathrm{kg}^{-1}$ and Group V received $1,900 \mathrm{mg} \mathrm{kg}^{-1}$ through oral intubation for duration of Eight weeks. Elevated plus maze was used to assay for anxiety-related behaviour of the wistar rats. The wistar rats were placed at the junction of the four arms of the maze, facing a closed arm, allowed to freely explore the maze and their behavior was recorded simultaneously for $5 \mathrm{~m}$ by means of a video camera. Results: Wistar rats treated with Aluminium Chloride had, increased faecal boli, increased number of time crossing close arm entries and increased average time spent in close arms; but decreased time (lesser time) spent in the open arm of the maze when compared with the control group. This in turn implies that the Aluminium treated groups were more anxious than the control groups in exploration of their activities on the Elevated plus maze. Conclusion: It was concluded that Aluminium Chloride exposure has negative effects on anxiety-related behaviour of wistar rats as indicated by increased rate of anxiety in aluminium treated rats.
\end{abstract}

Key words: Elevated Plus Maze (EPM), manufactured foods, Aluminum (Al), aluminium containing compounds, oppositely positioned, aluminium treated rats

\section{INTRODUCTION}

Aluminum $(\mathrm{Al})$ has the potential to be neurotoxic in human and animals. It presents in many manufactured foods and medicines and is also added to drinking water for purification purposes (Newairy et $a l ., 2009)$. Al is widely used in antacid drugs, as well as in food additives and tooth paste (Malekshah et al., 2005). Environmental pollution with different aluminium containing compounds, especially those in industrial waste expose people to higher than normal levels of $\mathrm{Al}$ (Kloppel et al., 1997). Particulate matters distributed by cement-producing factories contain, high amount of $\mathrm{Al}$ and animals and populations residing in the vicinity are exposed to the pollution (Fatima et al., 2001). Al is a possible contributing factor in Alzheimer's disease (Campbell, 2002). Evidence for the contribution of $\mathrm{Al}$ to Alzheimer's disease (AD, remains contradictory (Flaten, 2001; Gupta et al., 2005). However, epidemiological studies have indicated a link between $\mathrm{Al}$ in drinking water and $\mathrm{AD}$ and a variety of human and animal studies have implicated learning and memory deficits after $\mathrm{Al}$ exposure (Buraimoh et al., 2011a; Exley, 2005; Schmidt et al., 2001; Yokel, 2000). It has been shown clearly that aluminium accumulates in various mammalian tissues such as brain, bone, liver and kidney (Wills et al., 1993; Sahin et al., 1994) and is accompanied by renal failure (Alfrey, 1980) or associated with age (Gomez et al., 1997).

Although aluminum has been implicated in Alzheimer's disease, Parkinsonism, Dementia complex and causes extensive damage to the nervous system, to date the mechanism of $\mathrm{Al}$ neurotoxicity has not been fully elucidated (Niu et al., 2007). In recent researches, aluminum has been reported to accelerate oxidative damage to bio molecules like lipid, protein and nucleic

Corresponding Author: Buraimoh, A.A., Department of Human Anatomy, Faculty of Medicine, Ahmadu Bello University, Zaria, Nigeria 
acids (Jyoti et al., 2007). It was also reported that aluminium chloride could induce brain damage which may impair memory and learning as seen in Alzheimer disease (Buraimoh et al., 2011a). This element (Al) appears mainly in food products and in drinking water from both natural sources and treatment methods (Yokel and McNamara, 2001).

Anxiety is a general term for several disorders that cause nervousness, fear, apprehension and worrying. These disorders affect how we feel and behave and they can manifest real physical symptoms. Mild anxiety is vague and unsettling, while severe anxiety can be extremely debilitating, having a serious impact on daily life. Anxiety affects one-eighth of the total population world-wide and has become an important area of research interest in psychopharmacology during this decade. Anxiety is considered a problem when symptoms interfere with a person's ability to sleep or otherwise function. Generally speaking, anxiety occurs when a reaction is out of proportion with what might be normally expected in a situation. Benzodiazepines are the major class of compounds used in anxiety and they have remained the most commonly prescribed treatment for anxiety. However, the realization that benzodiazepines present a narrow safety margin between the anxiolytic effect and those causing unwanted side effects has prompted many researchers to evaluate new compounds in the hope that other anxiolytic drugs will have less undesirable effects (Grundman et al., 2007). Basic research of complex behaviour has led to a dramatic increase in the use of rodent behaviour tests (Crawley, 2007). The Elevated Plus Maze (EPM) has been described as a widely used behavioural assay for anxiety behaviour responses of rodents, mice or rats (Pellow et al., 1985). The aim of this experiment was to evaluate the effects that aluminium chloride could have on anxiety-related behaviour of Adult wistar rats.

\section{MATERIALS AND METHODS}

This research work was conducted in the Department of Human Anatomy, Faculty of Medicine, Ahmadu Bello University, Zaria, Kaduna State, Nigeria.

Experimental animals: Ten (10) Adult wistar rats were used for this experiment. The wistar rats were housed in a stainless steel cages maintained at standard environmental conditions (12-12h light-dark cycle with light on at AM) with sufficient food, water and under good ventilation. The wistar rats were kept for two weeks (14days) before commencement of administration. This was to enable them to acclimatize.

Experimental design: The wistar rats were divided into five groups: Control group was given distil water while the four Aluminium exposed groups were given various concentrations of aluminium chloride as follows: Group I was the Control:

- Group II received $475 \mathrm{mg} \mathrm{Kg}^{-1}$

- Group III received $950 \mathrm{mg} \mathrm{kg}^{-1}$

- Group IV received $1,425 \mathrm{mg} \mathrm{kg}^{-1}$

- Group V received $1,900 \mathrm{mg} \mathrm{kg}^{-1}$ (LD25)

The LD50 was $3,800 \mathrm{mg} \mathrm{kg}^{-1}$. The duration of administration was Eight weeks and the route of administration was through oral intubation.

The elevated plus maze: The Elevated Plus Maze (EPM) is a piece of equipment and protocol used by behavioural scientists to measure anxiety levels in laboratory rodents, Mice, rats. Different-sized mazes can be used for either rats or mice, but the same principles apply to each experiment. The elevated plus maze has four arms, arranged in a + shape; two of these arms have sides, so providing some shelter and a more secure feeling for the animal and the other two arms are open. The EPM apparatus consists of a plus shaped ("+") maze elevated above the floor with two oppositely positioned closed arms, two oppositely positioned open arms and a center area. The two opposite arms, $50 \times 50 \mathrm{~cm}$, crossed with two enclosed arms of the same dimension but having $40 \mathrm{~cm}$ high walls. The arms were connected with a central square, $10 \times 10 \mathrm{~cm}$, giving the apparatus shape of a plus sign. The maze was kept in a room and elevated $50 \mathrm{~cm}$ above the floor. Wistar rats were placed individually in the centre of the maze, facing an enclosed arm. Thereafter, number of entries and time spent on the open and enclosed arms were recorded during the next $5 \mathrm{~min}$. An arm entry was defined when all four paws of the wistar rats were in the arm. The premise behind the elevated plus maze is that more anxious rats will spend less time in the uncovered, exposed arms of the maze and less anxious rats will explore the open arms more freely (Shepherd et al.,1994).

Experimental procedure: After oral administration of various concentrations of Aluminium chloride to each group of the Wistar rats except group I (control) that received distill water, the wistar rats were placed at the junction of the four arms of the maze, facing an enclosed arm, allowed to freely explore the maze and their behaviour was recorded simultaneously for $5 \mathrm{~min}$ by means of a video camera mounted above the maze and the records analyzed. The preference for being in open arms over closed arms was calculated to measure anxiety-like behaviour and an increase in open arm activity (duration and/or entries) reflected anti-anxiety behaviour. 
Am. J. Neuroscience 2 (2): 65-69, 2011

Statistical analysis: SPSS for Windows Version 10.0 was used to perform one-factor Analysis of Variance (ANOVA) in order to compare the results of the treated with the control and to check whether the differences observed was statistically significant or not. The probability level was set at $\mathrm{p}<0.05$ (i.e., $95 \%$ confidence interval).

\section{RESULTS AND DISCUSSION}

Aluminium (Al) is one of the most abundant metals in the earth's crust. Human exposure to $\mathrm{Al}$ has been increasing over the last decades. This element appears mainly in food products and in drinking water derived from both natural sources and treatment methods (Yokel and McNamara, 2001).Drinking water contribution has been estimated to be ranging from 3$8 \%$ (WHO, 2002) Health Canada, 1997. Role of Al intoxication in different organs in neurodegenerative diseases has been recently emphasized (Somova et al., 1997; Exley, 1999). Buraimoh et al., 2011b stated that Aluminium chloride exposure has negative effects on behavioral endpoints of wistar rats (i.e., alters behaviour) and can impair learning and memory. In this study, the effects of Aluminum chloride on anxiety-like behavior in wistar rats were shown in Fig. 1-5. The locomotor activity of wistar rats was assessed by the number of crossing squares noted as scores per time of 5 min for each wistar rats. The numbers of times of entries of wistar rats into both opened and closed arms of the elevated plus maze significantly increased across the treated groups (Fig. 4-5 and Table 4-5). There was increase in defecation which may be due to heightened autonomic activity in the treated groups when compared with the control group (Fig. 3-5 and Table 3-5). There was also increased number of time crossing close arm entries (Fig. 4 and Table 4) and increased average time spent in close arms(Fig. 2 and Table 2); but decreased time (lesser time) spent in the open arm of the maze when compared with the control group (Fig. 1 and Table 1).

The preference for being in open arms over closed arms was calculated to measure anxiety-like behavior and an increase in open arm activity in control group (duration and/or entries) reflected anti-anxiety behaviour (Fig. 1 and Table 1). There was gradual significant decrease in open arm activity (duration/time spent in open arms) of the elevated plus maze from groups I to V. (Fig.1 and Table 1). This was eminent in the control group I, that exhibited an anti-anxiety behaviour (Increased open arms activity) when compared with the treated groups II to V (decreased open arms activity).
Table 1: Analysis of Variance of the time spent in open arms of the elevated plus maze

\begin{tabular}{lcccr}
\hline Groups & Count & Sum $(\mathrm{sec})$ & Average $(\mathrm{sec})$ & Variance \\
\hline X1 & 2 & 570 & 285 & 50 \\
X2 & 2 & 530 & 265 & 50 \\
X3 & 2 & 390 & 195 & 50 \\
X4 & 2 & 340 & 170 & 200 \\
X5 & 2 & 260 & 130 & 200 \\
\hline \multicolumn{2}{l}{ p-value $=0.000113$}
\end{tabular}

Table 2: Analysis of variance of the time spent in close arms of the elevated plus maze

\begin{tabular}{lcccr}
\hline Groups & Count & Sum $(\mathrm{sec})$ & Average $(\mathrm{sec})$ & Variance \\
\hline X1 & 2 & 30 & 15 & 50 \\
X2 & 2 & 70 & 35 & 50 \\
X3 & 2 & 210 & 105 & 50 \\
X4 & 2 & 260 & 130 & 200 \\
X5 & 2 & 340 & 170 & 200 \\
\hline \multicolumn{2}{l}{ p-value $=0.000113$} & & &
\end{tabular}

Table 3: Analysis of variance of the number of faecal boli

\begin{tabular}{lcccc}
\hline Groups & Count & Sum & Average & Variance \\
\hline X1 & 2 & 0 & 0.0 & 0.0 \\
X2 & 2 & 3 & 1.5 & 0.5 \\
X3 & 2 & 4 & 2.0 & 0.0 \\
X4 & 2 & 6 & 3.0 & 0.0 \\
X5 & 2 & 7 & 3.5 & 0.5 \\
\hline
\end{tabular}

P-value $=0.0003265$

Table 4: The number of time on close Arm entries

\begin{tabular}{lcccr}
\hline Groups & Count & Sum $(\mathrm{sec})$ & Average $(\mathrm{sec})$ & Variance \\
\hline X1 & 2 & 8 & 4.0 & 0.0 \\
X2 & 2 & 13 & 6.5 & 0.5 \\
X3 & 2 & 17 & 8.5 & 0.5 \\
X4 & 2 & 19 & 9.5 & 0.5 \\
X5 & 2 & 22 & 11.0 & 0.0 \\
\hline
\end{tabular}

P-value-0.000327

Table 5: The number of time on open Arm entries

\begin{tabular}{lcccc}
\hline Groups & Count & Sum $(\mathrm{sec})$ & Average $(\mathrm{sec})$ & Variance \\
\hline X1 & 2 & 4 & 2.0 & 0.0 \\
X2 & 2 & 8 & 4.0 & 0.0 \\
X3 & 2 & 11 & 5.5 & 0.5 \\
X4 & 2 & 16 & 8.0 & 0.0 \\
X5 & 2 & 18 & 9.0 & 0.0 \\
\hline P-value $=$ & 1.73 E-05 & & &
\end{tabular}

The preference of wistar rats for staying in closed arms over open arms observed in the treated groups was used as a measure of anxiety-like behaviour and hence Aluminium chloride in this study was implicated in anxiety-like behaviour unlike the control that showed preference for more exploration of open arms, showed by statistically significant increased time spent in open arms and less exploration of closed arms in control group when compared with the treated groups (Fig. 1 and 2; Table 1 and 2) and hence Aluminium may affect their learning ability as shown in Fig. 1 and Table 1. This agreed with the study of (Berlyne et al., 1972; Deloncle and Guillard, 1990) that stated that long-term administration of soluble salt of Aluminium to rats worsens their learning ability together with diminished cholinergic function and the rats become lethargic. 
Am. J. Neuroscience 2 (2): 65-69, 2011

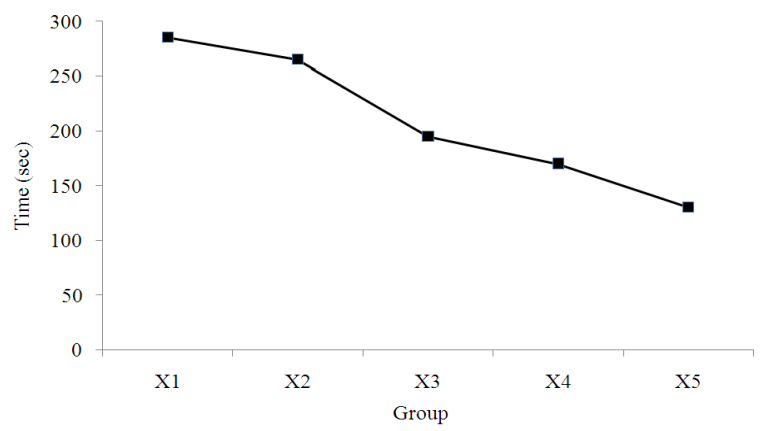

Fig. 1: Graph of average time spent in open Arms of the elevated plus maze

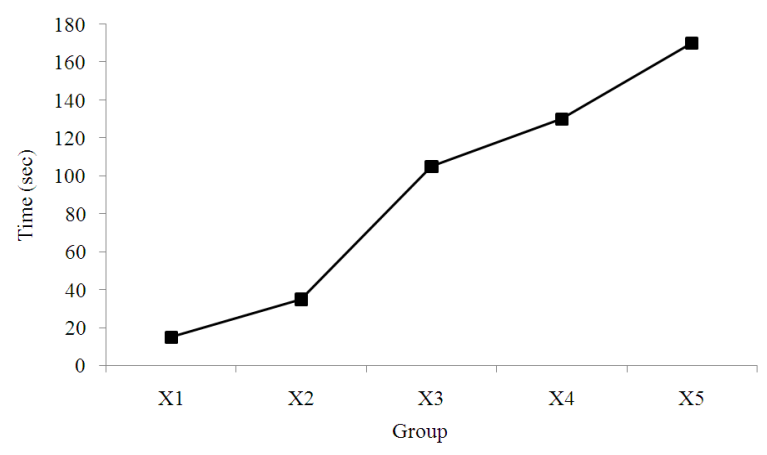

Fig. 2: Graph of average time spent in close Arms of the elevated plus maze

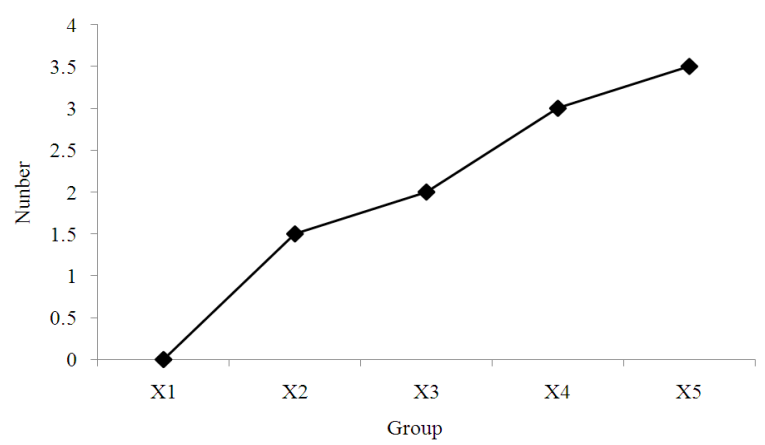

Fig. 3: Graph of the number of faecal boli

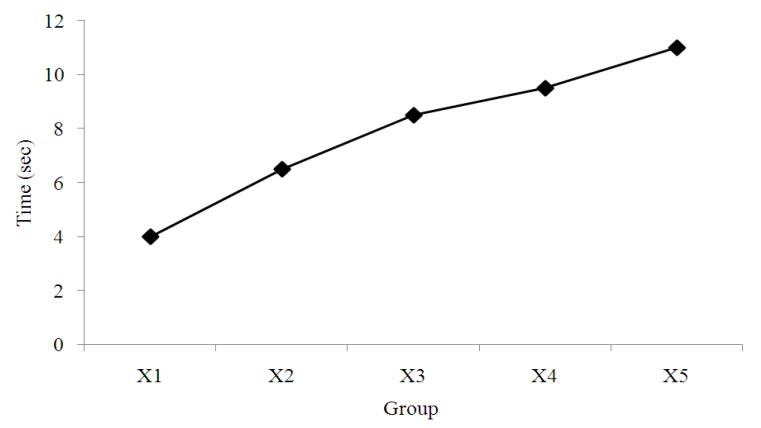

Fig. 4: Graph of number of time on close Arm entries

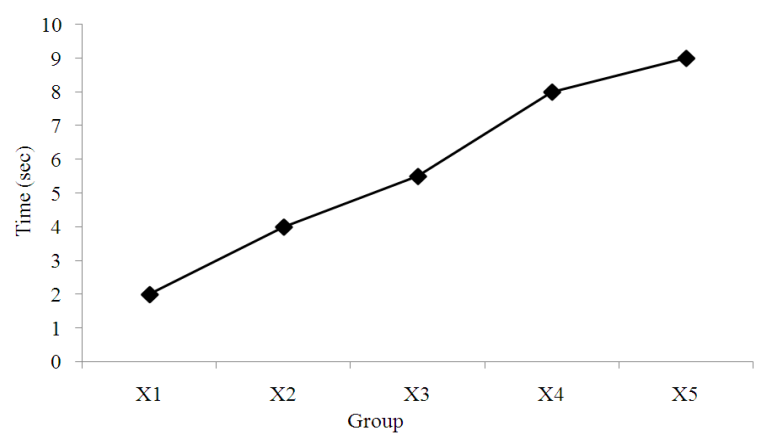

Fig. 5: Graph of the number of time on open Arm entries

Our observations revealed that the wistar rats treated with Aluminium Chloride had increased faecal boli across group, spent lesser time in the open arm of the maze and more time in closed arm than the control group and it was statistically significant at $\mathrm{p}<0.05$ (Table 1-3 and Fig. 1-3). This in turn indicated that the Aluminium treated groups were more anxious than the control groups in exploration of their activities on the maze (Fig. 1 and Table 1). Based on our observations, we therefore conclude that Aluminium Chloride exposure has negative effects on anxiety-related behaviour of wistar rats as indicated by increased rate of anxiety in aluminium treated rats.

\section{CONCLUSION}

It was concluded that Aluminium Chloride exposure has negative effects on anxiety-related behaviour of wistar rats as indicated by increased rate of anxiety in aluminium treated rats.

\section{ACKNOWLEDGMENT}

The researchers wish to acknowledge the Authority of Ahmadu Bello University, Zaria for supporting and providing an enabling environment for this research work.

\section{REFERENCES}

Malekshah, A.K., Z. Torabizadeh and F. Naghshwar, 2005. Developmental toxicity of aluminum from high doses of alcl3 in mice. J. Applied Res., 5: 575-579.

Alfrey, A.C., 1980. Aluminum metabolism in uremia. Neurotoxicology, 1: 43-53.

Berlyne, G.M., R. Yagil, J.B. Ari, G. Weinberger and E. Knopf et al., 1972. Aluminium toxicity in rats. Lancet, 7750: 564-568. PMID: 4110051

Buraimoh, A.A., S.A. Ojo, J.O. Hambolu and S.S. Adebisi, 2011a. Effects of oral administration of aluminium chloride on the histology of the hippocampus of wistar rats. Curr. Res. J. Biol. Sci., 3: 509-515. 
Buraimoh, A.A., S.A. Ojo, J.O. Hambolu and S.S. Adebisi, 2011b. Behavioural enpoints of adult wistar rats, following aluminium chloride exposure. Br. J. Pharmacol. Toxicol., 2: 273-276. ISSN: 2044-2467

Campbell, A., 2002. The potential role of aluminium in alzheimer's disease. Nephrol. Dial. Transplant., 17: 17-20. DOI: 10.1093/ndt/17.suppl_2.17

Crawley, J.N., 2007. What's Wrong with my Mouse?: Behavioral Phenotyping of Transgenic and Knockout Mice. 2nd Edn., Wiley-Interscience, New York, ISBN-10: 9780471471929, pp: 523.

Deloncle, R. and O. Guillard, 1990. Mechanism of alzheimer's disease: Arguments for a neurotransmitter-aluminum complex implication. Neurochem. Res., 15: 1239-1245. PMID: 1982955

Exley, C., 1999. A molecular mechanism of aluminium-induced Alzheimer's disease? J. Inorg. Biochem., 76: 133-140. DOI: 1016/S01620134(99)00125-7

Exley, C., 2005. The aluminium-amyloid cascade hypothesis and alzheimer's disease aluminium and $\beta$-amyloid. Alzheimer's Disease, 38: 225-234. DOI: 10.1007/0-387-23226-5_11

Flaten, T.P., 2001. Aluminium as a risk factor in Alzheimer's disease, with emphasis on drinking water. Brain Res. Bull., 55: 187-196. DOI: 10.1016/S0361-9230(01)00459-2

Gomez, M., D.J. Sanchez, J.M. Llobet, J. Corbella and J.L. Domingo, 1997. The effect of age on aluminum retention in rats. Toxicology, 116: 1-8. DOI: $10.1016 / \mathrm{S} 0300-483 \mathrm{X}(96) 03512-3$

Grundman, O., J.I. Nakajima, S. Seo and V. Butterweck, 2007. Anti-anxiety effects of Apocynum venetum $\mathrm{L}$. in the elevated plus maze test. J. Ethnopharmacol., 110: 406-411. DOI: 10.1016/j.jep.2006.09.035

Gupta, V.B., S. Anitha, M.L. Hegda, L. Zecca and R.M. Garruto et al., 2005. Aluminium in Alzheimer's disease: Are we still at a crossroad? Cell. Mol. Life Sc., 62: 143-158. DOI: 10.1007/s00018-0044317-3

Jyoti, A., P. Sethi and D. Sharma, 2007. Bacopa monniera prevents from aluminium neurotoxicity in the cerebral cortex of rat brain. J. Ethnophar., 111: 56-62. DOI: 10.1016/j.jep.2006.10.037

Kloppel, H., A. Fliedner and W. Kordel, 1997. Behaviour and endotoxicology of aluminium in soil and water. Rev. Sci. Lit. Chemos., 35: 353-363.

Newairy, A.S., A.F. Salama, H.M. Hussien and M.I. Yousef, 2009. Propolis alleviates aluminiuminduced lipid peroxidaion and biochemical parameters in male rats. Food Chem. Toxicol., 47: 1093-1098. PMID: 19425229
Niu, Q., Y . Yang, Q. Zhang, P. Niu and S. He et al., 2007. The relationship between $\mathrm{Bcl}-2$ gene expression and learning and memory impairment in chronic aluminum-exposed rats. Neurotoxicity Res., 12: 163-169. DOI: 10.1007/BF03033913

Pellow, S., P. Chopin, S.E. File and M. Briley, 1985. Validation of open: Closed arm entries in an elevated plus-maze as a measure of anxiety in the rat. J. Neurosci. Methods, 14: 149-167. DOI: 10.1016/0165-0270(85)90031-7

Sahin, G., I. Varol and A. Temizer, 1994. Determination of aluminium levels in the kidney, liver and brain of mice treated with aluminium hydroxide. Biol. Trace. Element Res., 41: 129-135. PMID: 7946900

Schmidt, M.L., V. Zhukavera, D.P. Perl, S.K. Sheridan and T. Schuck et al., 2001. Spinal cord neurofibrillary pathology in alzheimer disease and guam parkinsonism-dementia complex. J. Neuropathol. Exp. Neurol., 60: 1075-1086.

Fatima, S.K., P.A. Prabhavathi, P. Padmavathi and P.P. Reddy, 2001. Analysis of chromosomal aberrations in men occupationally exposed to cement dust. Mutat Res., 490: 179-186. DOI: 10.1016/S13835718(00)00165-0

Shepherd, J.K., S.S. Grewal, A. Fletcher, D.J. Bill and C.T. Dourish, 1994. Behavioural and pharmacological characterisation of the elevated "zero-maze" as an animal model of anxiety. Psychopharmacology, 116: 56-64. DOI: 10.1007/BF02244871

Somova, L.I., A. Missankov and M.S. Khan, 1997. Chronic aluminum intoxication in rats: Dosedependent morphological changes. Methods Find Exp. Clin. Pharmacol., 19: 599-604. PMID: 9500123

WHO, 2002. Guidelines for Drinking-Water Quality. 2nd Edn., World Health Organization, Geneva, ISBN-10: 9241544600, pp: 142.

Wills, M.R., C.D. Hewitt, B.C. Sturgill, J. Savory and M.M. Herman, 1993. Long-term oral or intravenous aluminum administration in rabbits. I. Renal and hepatic changes. I. Renal and hepatic changes. Ann. Clin. Lab Sci., 23: 1-16.

Yokel, R.A. and P.J. McNamara, 2001. Aluminium toxicokinetics: An updated minireview. Pharmacol. Toxicol., 88: 159-167. DOI: 10.1111/j.16000773.2001.880401.x

Yokel, R.A., 2000. The toxicology of aluminum in the brain. Neurotoxicology, 21: 813-828. PMID: 11130287 